\title{
A BRIEF LOOK ON THE LITERATURE ON DESEASONALIZATION
}

\author{
Julia Campos*
}

\section{Resumo}

Este trabalho apresenta questōes importantes relacionadas com procedimentos de eliminação das variaçōes sazonais para variáveis econômicas. Conclui-se que (i) a análise separada dos movimentos de curto prazo dos movimentos de longo prazo associados às séries econômicos temporais pode ser útil em análises de política econômica; (ii) ainda existem dificuldades não-solucionadas no que concerne às definiçōes apropriadas para os componentes; (iii) se o procedimento X-11 for utilizado, sugere-se então o uso da previsão X-11 associada com a atualizaçāo corrente e (iv) em modelagem econométrica existem várias razôes para a utilizaçāo de dados não-ajustados para as variaçōes sazonais ao invés de dados ajustados sazonalmente.

\begin{abstract}
This paper presents the issues related to seasonality patterns and deseasonalization procedures of economic variables. The paper concludes claiming that: (i) analysing long-term movements of economic time series separately from short-term ones may be useful for economic policy analysis; (ii) there is an yet unresolved difficulty in finding suitable definitions for the components; (iii) if the $\mathrm{X}-11$ procedure is to be used, then the $\mathrm{X}-11$ forecast plus current updating is suggested; (iv) there are several reasons for using seasonally unajusted data for econometric modelling rather than deseasonalized data.
\end{abstract}

\section{Introduction.}

For a long time, economic time series have been viewed as composed of unobserved factors: trend, cycle, seasonal and irregular. Aside from the feeling that by such a decomposition authors attempt to explain movements of economic data without much concern about agents' behaviour (although see Ghysels 1990), three issues become fundamental: (i) defining those components, (ii) why economists may be interested in separating them and (iii) how much and what a deseasonalization procedure must remove from a series or what criteria

\footnotetext{
*Banco Central de Venezuela. The views in this paper do not necessarily reflect those of the Banco Central de Venezuela. I am grateful to a referee for useful comments. However, errors are the sole responsability of the author.
}

\begin{tabular}{llll}
\hline R. de Econometria & Rio de Janeiro & v. $11, \mathrm{n}^{\circ}$ 2, p.217-236 novembro 1991
\end{tabular}


such a procedure must satisfy to be regarded as adequate. This is the concern of Section 2: In addition, the issue of whether adjusted data are suitable for econometric modelling is also addressed by the literature and so Section 3 refers to it. Section 4 describes regression and filtering methods used for seasonal adjustment and refers to criteria employed for assessing their suitability. Finally, Section 5 offers the conclusions.

\section{Three issues related to seasonal adjustment.}

The trend is defined as that tendency of a time series to increase (or decrease) steadily over time. This kind of trend is usually called trend in mean. There could be a trend in variance, i.e., changes in the oscillation of the series about a (possibly trending) mean. Changes in the importance of a series component are also known as trend as they representa change in the series autocorrelation pattern (see Granger and Hatanaka 1964, pp.12-13). The cycle is a movement of quasiperiodic appearance with an increasing phase followed by a decreasing one (see Malinvaud 1970, pp.440). Seasonality is interpreted as a fairly regular movement of a series within a year (see Priestley 1981, pp.597). Thomas and Wallis (1971) make the latter definition slightly more precise by qualifying those movements as systematic as well as being caused by non-economic phenomena. Climatic changes, regular timing of religious festivale or other public holidays determining the number of trading days, timing decisions (timing of school vacations, payments of company dividends, etc.) and expectations of a seasonal pattern in a variable are mentioned as causes of seasonal variation (see Granger 1978). The irregular component is viewed as those unforecastable movements of a more or less stable random appearance (see Malinvaud 1970, p. 440). Impact of some political events, effects of strikes, unseasonable weather conditions, etc., are regarded to be irregular factors (see Shiskin et al. 1967).

The definitions above are not very useful in practice. However, translating them into working concepts is difficult and even more so if the seasonal pattern changes over time. Indeed, Durbin (1983) defines the trend-cycle component as that underlying systematic part of the series remaining after the seasonal and irregular factors have been removed pointing out that since the latter are not well defined, there cannot be a useful definition of the former. Thus, the trend is what- 
ever is left after smoothing the series with the degree of smoothing depending upon the researcher's judgement.

Turning to (ii), economists have argued that separate factors provide different sorts of information. In addition, factors are affected to different extents by economic policies and/or by movements of the components of other series (see Nerlove 1967 and Ghysels 1990). Seasonal factors are those components, predictable but extraneous to the system, representing the effect of non-economic factors. Yet, they may be useful, e.g., for planning production schedules, as estimates of unused resources over seasonally low periods, and for designing suitable policies to preclude undesired seasonal fluctuations in other economic variables (see Wallis 1974, 1982, Shiskin 1969 and Maravall 1984a). Seasonal factors usually contribute very strongly to the total variance of the series, smearing the trend-cycle. Hence, seasonal factors must be removed to analyse policy effects on long term movements of economic variables.

Answering (iii) is not much easier and in fact difficulty arises from the vague replies to (i) and (ii). A series is deseasonalized by obtaining an estimate of the seasonal factor and subtracting it from the original series (or dividing the original series by it for a multiplicative model). How much and what a deseasonalisation procedure must remove is closely related to the definition of seasonality. Wallis (1974) (see also Lovell 1963) points out that seasonal adjustment must remove the seasonal component without distorting the remainder. Seasonal variation might also be identified as causing peaks in the spectrum at some frequencies (see Nerlove 1964, Granger 1978, Granger and Newbold 1977, p.65 and Burman 1980). However, unless the seasonal component had positive power only at the seasonal frequencies, removing those peaks entails that the spectral density of the non-seasonal component will be under that of the original series at other frequencies (see Nerlove et al. 1979, p.151 and Burman 1980). In addition, peaks at those frequencies may also be found in ARMA processes (see Nerlove 1967, p.140, Granger and Newbold 1977, p.65 and Ghysels 1988).

A further point can be made in addition to (i)-(iii); seasonal adjustment is usually carried over individual series even though a relationship may exist between components of different series (see Nerlove et al. 1979). For instance, whether a series varies seasonally 
may depend upon other series having seasonal components; Maravall (1982) illustrates this matter by looking at a policy effect on money stock after a seasonal increase in money demand. The policy adopted in his example will determine seasonal movements either in money or interest rates or both. As a further example, weather may cause production of a good to vary seasonally leading to a seasonal factor in the associated price series (see Granger 1978). Such a relationship between seasonal components may be more intricate. This leads naturally to the following section.

\section{Seasonal adjustment and econometric modelling.}

Before analysing seasonal adjustment procedures, something must be said about deseasonalising individual time series and its implications on relationships between them when those relationships are assumed to hold over unadjusted variables. It has been found that model specification varies according to using raw or adjusted data. Information may be lost by separately deseasonalising variables since their seasonal components may be related, model mis-specification may result from a failure to fully account for seasonality and nonstationarity may be induced on adjusted data (see Plosser 1979 and Wallis 1982). In addition, properties of estimation methods may be impaired if applied to models on adjusted data.

If seasonality in the dependent variable were not entirely a consequence of seasonality in the explanatory variables, under standard assumptions, the OLS regression postmultiplied by the annihilator of the matrix of all seasonal variables would be equivalent to the OLS regression with unadjusted data including seasonal variables as regressors (see Thomas and Wallis 1971). However, there is an advantage from doing it the latter way: the number of degrees of freedom remaining after estimation is clearly determined so that the error variance is not underestimated and hence the significance of parameters is not overstated. Also, whether seasonal variation is accounted for in its entirety by the other explanatory variables can be tested by looking at the significance of seasonals and indirectly by checking against residual autocorrelation at seasonal lags, since the disturbances must include everything not specified in the systematic part of the model. This is a relevant issue because, unless seasonals were orthogonal to the remaining explanatory variables, invalid exclusion there of biases 
OLS estimates and wrong inclusion makes those estimates inefficient.

If seasonality were entirely determined by the regressors seasonal variation, even using the same filters would cause disturbances to be autocorrelated and hence OLS with adjusted variables would be inefficient and might even be inconsistent. Hence, using adjusted data in this case has, at the least, the same effect on OLS estimates as invalidly including seasonal variables in the model. In addition, the OLS expression for the asymptotic variance matrix may be biased depending upon signs and magnitudes of the autocorrelations induced by seasonal adjustment on the exogenous variables and disturbances. Notice that those autocorrelations may compensate each other and hence the correct value of the variances may be obtained. If different filters were used, besides the errors becoming autocorrelated, the right hand side variables distributed lags would change in terms of dynamics and parameters (see Wallis 1974).

OLS would also be inconsistent if the right hand side variables had seasonal components which are independent of their non-seasonal factors and unrelated to the dependent variable. However, previous adjustment of the explanatory variables would not in general solve the problem because the spectral density of the adjusted variables would not necessarily equal that function for their non-seasonal component (see Wallis 1974; see Appendix A). Even if the dependent variable were actually a function of the seasonal component, and the adjusted explanatory variables were good approximations to their non-seasonal factors, the adjusted regressors would not be orthogonal to the estimated seasonal components (computed as the difference between the original and the filtered series). Hence, regressing the unadjusted dependent variable on the adjusted regressors would lead to inconsistent estimates because the disturbances (containing the estimated seasonal component) would be correlated with the adjusted regressors (see Wallis 1978).

Further results on the consequences of deseasonalization for econometric work have recently been obtained for univariate ARMA processes. Those results are concerned with the properties of OLS, and those of the Dickey-Fuller's (DF) and Phillips-Perron's (PP) statistics,designed to test for unit roots. If the ARMA process were non-seasonal and had a unit root, filtering would not alter the distribution of DF and PP, and OLS would be consistent but with a dif- 
ferent asymptotic distribution. However, if the ARMA process were stationary, no matter whether it was seasonal or not, OLS would be inconsistent showing an upward bias in large samples. This positive bias would entail a reduction in the power of DF and PP (see Ghysels and Perron 1990).

Although there are cases in which prior seasonal adjustment may be advantageous, (e.g., when seasonality in the dependent variable arises from seasonality in the disturbances, adjusting all data by the filter which deseasonalises the disturbances would lead to more efficient estimates since applying OLS to adjusted data would be equivalent to applying GLS to original data (see Wallis 1974)), there is much to be gained from incorporating seasonality into econometric models with original data since a complete econometric model must be useful for deciding about what is causing seasonality and what is making it to vary over time. Also, even if seasonality were fully accounted for, some variables are seasonal whereas others are not and mixing them in a relationship may change the dynamics and hence lead to distortions of the economic analysis (see Plosser 1978). Plosser (1979) suggests several ways of introducing seasonality in a model depending upon what is causing it. Zero-one dummy variables are often used when seasonality is due to a changing mean. Seasonality may also be induced by seasonal parameters and hence the matrix of coefficients of the endogenous variables can be specified as consisting of seasonal lag-polynomials which would creat lags in the endogenous variables.

\section{Methods for seasonally adjusting economic time series.}

i) Criteria for assessing their reliability

Adjustment procedures based on regression analysis and moving average filtering have been developed in the last thirty years or so, along with sets of desirable properties. Shiskin and Eisenpress (1957) suggest that a good procedure must minimizc repetitive intrayear movements without changing the location of turning points, amplitudes and patterns of busincss cycles. Lovell (1963) looks at preservation of sums and products, orthogonality, idempotency and symmetry. An adjustment procedure is said to be sum (product) preserving if the sum (product) of seasonally adjusted variables equals the adjusted sum (product) of those variables, i.e., if a procedure is sum preserving the adjusted log of the unemployment rate must equal 
the difference between the adjusted log of the number of unemployed and the adjusted log of the labour force. A procedure is orthogonal if the seasonally adjusted series is uncorrelated with the seasonal component of the original series, i.e., seasonal and non-seasonal factors are uncorrelated with each other. It is idempotent if the same seasonally adjusted series results when the filter is repeatedly applied. However, an adjustment procedure cannot be both sum and product preserving unless adjusted and original series equal each other. In addition, it may be hard to find a filter which does not alter the series in each successive application. Further, orthogonality assumes that seasonal and non-seasonal components enter additively (see Nerlove et al. 1979, pp.163-164). Some seasonal adjustment computer packages provide diagnostic tests for assessing the reliability of estimated seasonal factors. Additional criteria are provided by Findley and Monsell (1986).

Nerlove $(1964,1965)$ states some criteria in the frequency domain. The coherence between the original and seasonally adjusted series must be close to one, except probably at seasonal frequencies preserving so the linear association between the input and output series (see Fishman 1969, pp.69-70). Phase shifts should be minimized keeping in mind that zero coherence implies an approximately uniformly distributed phase on $[-\pi / 2, \pi / 2]$ so that a non-zero phase may be expected at frequencies corresponding to low coherence (see Rosenblatt 1968 and Grether and Nerlove 1970). Additional phase shifts are undesirable because they change the timing between the phases of the contributions to the frequencies, entailing filtered series with business cycles turning down before they actually do in the unadjusted series (see Fishman 1969, p.43). Peaks at seasonal frequencies must be removed (at the level of the contribution of the irregular componet, see Rosenblatt 1968) without affecting power at other frequencies (see also Granger and Newbold 1977). Rosenblatt (1968) adds orthogonality to those criteria, meaning that the co-spectrum of the seasonally adjusted series and the seasonal component must be zero at all frequencies.

Aside from what has been pointed out in Section 2 on the suitability of these criteria for assessing the adequacy of a seasonal adjustment procedure, coherence may be below unity at non-seasonal frequencies for models of the seasonal component with a non-zero 
spectrum at frequencies other than seasonal. On the other hand, any filter defined as a linear combination of past and (possibly) future values of the series with constant coefficients would render unity coherence (see Grether and Nerlove 1970).

Estimated seasonal components are subject to revisions as new data becomes available. Because we would like the estimates to change as little as possible, properties of the revisions of estimated seasonal factors have also been considered for assessing the reliability of seasonal adjustment procedures. Most of those procedures use past and future observations to adjust economic time series, so that the adjusted current and recent data must be revised as future information accrues. Under the assumption that seasonal and non-seasonal componets follow MA or integrated MA processes and that estimated seasonal factors are obtained by minimizing the mean square error of estimation, it can be shown that revisions and the earliest estimated seasonal factor are mutually independent and uncorrelated with the final estimation error. It can also be shown that revisions follow an infinite MA process for non-optimal seasonal adjustment procedures which are linear filters of the available data (with such a process being finite under some additional assumptions, see Pierce 1980).

Wallis (1982) compares symmetric to asymmetric filters in terms of square gains and phase shifts, looking in addition at the characteristics of the revisions in the frequency domain. The square gain measures the degree in which the filter modifies the contibution of a particular frequency component to the variance of the series being adjusted, i.e., the degree of amplification or attenuation of the amplitudes of the components of the series (see Fishman 1969, p.44). If low frequency contributions are amplified and high ones are attenuated, the filtered series will show less variation over short time intervals and more over long time intervals implying an increase in autocorrelation.

In the time domain Pierce and McKenzie (1987) compare seasonal adjustment procedures in terms of mean square errors of revisions. Wallis (1983) looks at filters internal consistency with respect to a particular original series-process. A set of filters is internally consistent with respect to a given process for the series if the asymmetric filter minimizing the mean square of revisions results from applying a symmetric filter to a series extended by the optimal lin- 
ear forecasts of the series unknown values. A set of filters satisfying this property minimizes the mean square of revisions throughout the whole sequence of adjustments.

Ways of improving extant seasonal adjustment procedures have also been looked at. Besides using past data to compute seasonal factors for adjusting that same data, past data are also used to compute a seasonal factor for each period of the following year. Those are called "year ahead" factors. Instead, the original series may be extended by a number of forecast values and year ahead factors computed once a year based on that augmented series. For optimal forecast values, applying a symmetric filter to that augumented series is equivalent to filtering the series using the asymmetric filter with smallest mean square error of revision. In addition, current updating may be performed, i.e., readjustment can be carried out as soon as a new data point is available instead of adjusting the data just once a year.

ii) Description of adjustment procedures

In what follows, a brief reference is made to least-square, modelbased and ratio-to-moving average methods for deseasonalising economic time series. Of the latter only X-11 is described because of the enormous amount of literature devoted to studying its properties. Other methods are described by Kuiper (1978). (See also Cleveland et al., 1978.)

Adjustment by least square methods is said to be optimal for series showing deterministic seasonality (i.e., predictable without error from previous periods seasonal factors (see Pierce 1978) and is accomplished by running a regression of the series to be adjusted on a set of explanatory variables. Lovell (1963) shows that the residual series from a such regression coincides with the adjusted variable and satisfies the properties of sum preservation, idempotency, orthogonality and symmetry. Jorgenson (1964) decomposes a time series into a deterministic trend and seasonal, and a random factor which is assumed to have zero mean and to be serially uncorrelated. The seasonal and non-seasonal deterministic components are assumed to be linear combinations of a set of fixed variables, so that OLS is applied to obtain seasonal and trend parameter estimates. Lovell (1966) argues that the latter procedure does not satisfy the properties of symmetry and orthogonality and hence seasonality might not 
be completely removed. (See also Pierce 1978) on estimating and testing for deterministic seasonality).

Adjusting by moving average filtering has been done by signal extraction or by a ratio-to-moving-average procedure with both methods being suitable for series with stochastic seasonality. In addition, a Kalman filter approach has also been developed which, for stationary series, happens to be equivalent to signal extraction (see Burridge and Wallis 1985, 1990). In a signal extraction method, the unobserved component to be estimated (seasonal or trend) is expressed as an unknown linear combination of the observed series with the coefficients being estimated by minimizing (with respect to those coefficients) the mean square of the difference between the unobserved component and the associated linear combination. Procedures using signal extraction theory have been developed with seasonal and non-seasonal components being modeled as ARIMA processes. Those methods are known as model-based methods. Among others, Grether and Nerlove (1970), Pierce (1978), Burman (1980), Hillmer and Tiao (1982) and Hillmer et al. (1983) deal with model-based seasonal adjustment. In particular, in the latter two papers a canonical decomposition is proposed so that the implied ARIMA process for the observed time series can be identified. Once the ARIMA process for the original series has been identified and estimated, a unique decomposition of that process can be found by maximizing the variance of the innovations of a previously specified process for the noise component subject to a constraint (implied by the restrictions imposed on the processes of all components) on the raw series process. Such a decomposition minimizes the variances of the innovations of the seasonal and trend processes and that of the AR part of the seasonal factor. In addition, the canonical components differ from any other decomposition by a white noise series. However, the canonical decomposition maximizes the variance of revisions (see Maravall 1986 and Maravall and Pierce 1987). Hillmer et al. (1983) also propose procedures for removing trading-day and Easter holidays variations and the effect of outliers. With minor changes, a method of this kind has been programmed at the Bank of England (see Burman 1980, 1983). Most model adjustment has been based on modelling the components by ARIMA processes with a constant autocovariance structure. This assumption entails, in particular, a constant variance for the seasonal component. 
However, it has often been found that this variance changes with the season. Burridge and Wallis (1990) tell us how to deal with periodc models, so that allowance for seasonally varying variances can be made (see also Osborn 1991).

The ratio-to-moving-average deseasonalizing procedure $\mathrm{X}-11$ is a well known and perhaps the most widely used method. Under the assumption that economic time series can be multiplicatively or additively decomposed into a trend-cycle, a seasonal and an irregular component, X-11 provides an estimate for each factor. Estimates are obtained after a 2-stage procedure by applying different sorts of MA filters to the series, with intermediate checks for extreme values based on the irregular component. The sequence of estimates is: (i) trend-cycle, (ii) seasonal-irregular, (iii) seasonal, (iv) irregular and (v) deseasonalized series.

As described by Shiskin et al. (1967), X-11 provides a first estimate $\left(T C_{1}\right)$ of the trend-cycle by applying a centered 12-term MA to the original series $(O S)$. Next, a first estimate $\left(S I_{1}\right)$ of the seasonalirregular factor is computed by dividing the original series by $T C_{1}$ (i.e., $\left.S I_{1}=O S / T C_{1}\right)$. Following that, a first estimate $\left(S_{1}\right)$ of the seasonal component is given by sequentially applying two filters to $S I_{1}$. Those filters are a weighted 5-term MA and a centered 12 - term MA. Having estimated the seasonal factor, a first estimate $\left(S A_{1}\right)$ of the seasonally adjusted series is calculated as the ratio of the original series to $S_{1}$ (i.e., $S A_{1}=O S / S_{1}$ ). Before proceeding to the second stage, X-11 computes intermediate estimates of the trend-cycle and the irregular component in the following manner: the intermediate estimate $\left(T C_{i}\right)$ of the trend-cycle is computed by applying a 13-term Henderson MA to $S A_{1}$ and the intermediate estimate $\left(I_{i}\right)$ of the irregular factor results from dividing the adjusted series by $T C_{i}$ (i.e., $\left.I_{i}=S A_{1} / T C_{i}\right)$. Those intermediate estimates are used to compute the irregular to trend-cycle ratio which determines the length of the Henderson MA to be applied to $S A_{1}$ to obtain a final estimate $\left(T C_{f}\right)$ of the trend-cycle. Thus, a 9-, 13- or a 23-term Henderson MA (a 5-term one for quarterly series) is applied to the deseasonalized series $S A_{1}$ yielding $T C_{f}$. Again, a final estimate $\left(S I_{f}\right)$. of the seasonalirregular component is computed as the ratio $S I_{f}=O S / T C_{f}$ and the final seasonal factor estimate $\left(S_{f}\right)$ is obtained by sequentially applying two filters (a weighted 7-term MA followed by a centered 
12-term MA) to $S I_{f}$. Finally, the seasonally adjusted series is obtained by dividing the original series by $S_{f}$ (i.e., $S A_{f}=O S / S_{f}$ ). In addition, adjustment for trading day variation (not available for quarterly series), strikes, etc. can be performed and hence further sets of estimates for trend-cycle, seasonal, irregular and seasonally adjusted series is obtained.

The performance of $\mathrm{X}-11$ has been investigated by looking at the characteristics of some of the filters used by that method (see Wallis 1982). A symmetric filter was found to have a zero phase shift and a square gain very close to unity at low frequencies showing that the contibution of the components at those frequencies is nearly unchanged. It has a zero value at the seasonal frequencies. Asymmetric filters show small phase shifts except at frequencies close to the seasonal ones. Asymmetric filters show a square gain different from unity before the first seasonal frequency, oscillating around unity at other frequencies.

An X-11/ARIMA version has also been developed in which future values are forecasted by using ARIMA models so that current observations are adjusted by X-11 applied to series extended by forecasts (see Dagum 1978). Other forecast methods may also be used such as Holt-Winters and stepwise regression procedures. This X-11 extended version is shown to overperform ordinary X-11 (see Kenny and Durbin 1982). Dagum (1982) compares X-11 to X-11/ARIMA in terms of their filters frequency response functions, finding that for both procedures asymmetric filters (i.e., those used for current and recent data) show small phase shifts, except at frequencies around the fundamental $(2 \pi / 12)$ and its first harmonic $(4 \pi / 12)$. However, the gain is larger for ordinary X-11 entailing larger revisions of the adjusted series as data becomes available.

Aside from the difficulties involved in identifying an ARIMA process for the original series, the underlying statistical assumptions for model-based procedures are clearly set out and hence improvements can be made by relaxing or changing those assumptions. On the contrary, $\mathrm{X}-11$ is an empirically developed procedure and hence one whose properties are difficult to examine. However, Cleveland and Tiao (1976) show that if the unadjusted series follows a particular process, X-11 renders results comparable to those obtained from a modelbased procedure (see also Burridge and Wallis 1982). Based on that, 
Pierce (1980) specifies ARMA processes for some series and computes the variances of revisions. Values of the revisions themselves are also compared for an approximating method to X-11/ARIMA, the actual $\mathrm{X}-11$ /ARIMA and ordinary X-11. Although, his results do not consistently recommend any of those methods, Kenny and Durbin (1982) find that applying X-11 to the augumented series and/or using current updating leads to better results than those obtained from ordinary X-11, with errors being comparatively lower the farther away periods are from the last figure available and the higher the values of the month of cyclical dominance (MCD) are. (See Burridge 1982, for a definition of MCD). Moreover, current updating appears best, and indeed, the use of augmented series combined with current updating is suggested (see also Wallis 1980, 1983). Pierce and McKenzie (1987) show that concurrent adjustment (i.e., adjusting with current updating) together with X-11/ARIMA has smaller root mean square revisions than year-ahead adjustment. The difference between the two procedures becomes larger for periods farther away in the future. Wallis (1982) argues that the performance of X-11/forecast methods improves relative to ordinary $\mathrm{X}-11$, if the process providing the forecasts is close to the process generating the series and if the latter process differs from that generating the weights defined in ordinary $\mathrm{X}-11$.

$\mathrm{X}-11$ procedures are also compared to model-based methods by Hillmer et al. (1983) in terms of mean square errors of revisions for a particular process generating the original series. That process is used to forecast values so that symmetric filters can be used when applying $\mathrm{X}-11$. Which method is best depends upon the parameter values of the process of the original series. However, in terms of additional proposed measures model-based procedures perform better than X11. Maravall (1984b) compares X-11/ARIMA with Burman's (1980) deseasonalization method finding that both procedures yield revisions of nearly the same magnitudes and noisy deseasonalized series (see also Maravall 1984c).

More recently, a major revision of X-11 ARIMA was undertaken (see Findley et al. 1988). The new version called X-12 ARIMA includes new measures of the procedure's reliability in an attempt to compensate for the inadequacies of the already included diagnostic tests. 


\section{Conclusions.}

A brief look at the literature on deseasonalization leads to the following conclusions:

i) Analysing long-term movements of economic time series separately from short-term ones may be useful for economic policy analysis.

ii) There is an yet unresolved difficulty in finding suitable definitions for the components.

iii) More recent research seems to be oriented towards developing model-based procedures. However, if X-11 is to be used, X11 /forecast plus current updating is suggested.

iv) Finally, there are several reasons for prefering seasonally unadjusted data for econometric modelling. Some of them are related to the properties of estimation and testing procedures and others to changes induced by seasonal adjustment on the properties of the data and on the relationships between economic data.

\section{References}

Burman, J.P. 1980. "Seasonal adjustment by seasonal extraction." Journal of the Royal Statistical Society A 143:321-337.

1983. "Comments on modelling considerations in seasonal adjustment of economic time series, by S.C. Hillmer, W.R. Bell and G.C. Tiao." In Zellner, A. ed., Applied Time Series Analysis of Economic Data. Proceedings of the Conference on Applied Time Series Analysis of Economic Data 1981, US Department of Commerce, Bureau of Census..

Burridge, P. 1982. "Discussion to the paper 'Local trend estimation and seasonal adjustment of economic and social time series'." Journal of the Royal Statistical Society A 145:33-34.

Burridge, P. \& Wallis, K.F. 1982. "Unobserved-components models for seasonal adjustment." Journal of Business and Economic Statistics 2:350-59.

1985. "Calculating the variance of seasonally adjusted series." Journal of the American Statistical Association 20:541-52.

1990. "Seasonal adjustment and Kalman filtering: extension to periodic variances." Journal of Forecasting 2: 109-118. 
Cleveland, W.S., Dunn, D.M. \& Terpening, I.J. 1978. "SABL: a resistant seasonal adjustment procedure with graphical methods for interpretation and diagnosis." In Zellner, A. ed., Seasonal Analysis of Economic Time Series. Proceedings of the Conference on Seasonal Analysis of Economic Time Series 1976, US Department of Commerce, Bureau of Census..

Cleveland, W.S. \& Tiao, G. C. 1976. "Decomposition of seasonal time series: a model for the Census X-11 Program." Journal of the American Statistical Association 71:581-587.

Dagum, E.B. 1978. "Comments on a Survey and comparative analysis of various methods of seasonal adjustment by John Kuiper." In Zellner, A. ed., In Seasonal Analysis of Economic Time Series. Proceedings of the Conference on Seasonal Analysis of Economic Time Series 1976, Us Department of Commerce, Bureau of Census..

1982. "The effects of asymptotic filters on seasonal factor revisions." Journal of the American Statistical Association 77: 732-38.

Durbin, J. 1983. "Theory and practice in time series analysis." In Zellner, A. ed., Applied Time Series Analysis of Economic Data. Proceedings of the Conference on Applied Time Series Analysis of Economic Data 1981, US Department of Commerce, Bureau of Census..

Findley, D.F. \& Monsell, B. C. 1986. "New techniques for determining if a time series can be seasonally adjusted reliably." In Perryman, M.R. \& Schmidt, J.R. ed., Regional Econometric Modeling. Lancaster: Kluwer-Nijhoff Publishing.

Findley, D.F., Monsell, B.C., Otto, M.C., Bell, W. R. \& Pugh, M. G. 1988. "Toward X-12 ARIMA." In Proceedings of the Fourth Annual Research Conference. Bureau of Census..

Fishman, G.S. 1969. Spectral Methods in Econometrics. Cambridge, Massachusetts: Harvard University Press.

Ghysels, E. 1988. "A study toward a dynamic theory of seasonality for economic time series." Journal of the American Statistical Association 83:168-172.

1990. "On the economics and econometrics of seasonality." Mimeo, University of Montreal.

Ghysels, E. \& Perron, P. 1990. "The effect of seasonal adjustment 
filters on tests for a unit root." Mimeo, University of Montreal and Princeton University.

Granger, C.W.J. 1990. "Seasonality: causation, interpretation and implications." In Zellner, A. ed., Seasonal Analysis of Economic Time Series. Proceedings of the Conference on Seasonal Analysis of Economic Time Series, 1976, US Department of Commerce, Bureau of Census..

Granger, C.W.J. \& Hatanaka, M. 1964. Spectral Analysis of Economic Time Series. Princeton: Princeton University Press.

Granger, C.W.J. \& Newbold, P. 1977. Forecasting Economic Time Series. New York: Academic Press.

Grether, D.M. \& Nerlove, M. 1970. "Some properties of 'optimal' seasonal adjustment." Econometrica 38: 683-703.

Hillmer, S. C., Bell, W. R. \& Tiao, G. C. 1983. "Modelling considerations in seasonal adjustment of economic time series." In Zellner, A. ed., Applied Time Series Analysis of Economic Data. Proceedings of the Conference on Applied Time Series Analysis of Economic Data 1981, US Department of Commerce, Bureau of Census..

Hillmer, S. C. \& Tiao, G. C. 1982. "An ARIMA-model-based approach to seasonal adjustment." Journal of the American Statistical Association 77:63-70.

Jorgenson, D.W. 1964. "Minimum variance, linear unbiased seasonal adjustment of economic time series." Journal of the American Statistical Association 59:681-724.

Kenny, P.B. \& Durbin, J. 1982. "Local trend estimation and seasonal adjustment of economic and social time series." Journal of the Royal Statistical Society A 145:1-41.

Kuiper, J. 1978. "A survey and comparative analysis of various methods of seasonal adjustment." In Zellner, A. ed., Seasonal Analysis of Economic Time Series. Proceedings of the Conference on Seasonal Analysis of Economic Time Series 1976, US Department of Commerce, Bureau of Census..

Lovell, M.C. 1963. "Seasonal adjustment of economic time series and multiple regression analysis." Journal of the American Statistical Association 58:993-1010.

1966. "Alternative axiomatizations of seasonal adjustment." Journal of the American Statistical Association 801-802. 
Malinvaud, E. 1970. Statistical Methods of Econometrics. Amsterdam: North-Holland.

Maravall, A. 1982. "On the political economy of seasonal adjustment and the use of univariate time-series methods." Servicios de Estudios del Banco de España, № 8204.

1984a. "On issues involved with the seasonal adjustment of time series." Documento de Trabajo 8408, Banco de España.

1984b. "Analisis de las series de comercio exterior." Documento de Trabajo 8409, Banco de España.

1984c. "Model-based Treatment of a Manic-depressive Series." Documento de Trabajo 8407, Banco de España.

1986. "Revisions in ARIMA signal extraction." Journal of the American Statistical Association 81:736-740.

Maravall, A. \& Pierce, D.A. 1987. "A prototypical seasonal adjustment model." Journal of Time Series Analysis 8,2:177-193.

Nerlove, M. 1964. "Spectral analysis of seasonal adjustment procedures." Econometrica 32:241-286.

1965. "A comparison of a modified Hannan and the BLS seasonal adjustment filters." Journal of the American Statistical Association 60:442-91.

1967. "Distributed lags unobserved components in economic time series." In Fellner et al., Ten Economic Studies in the Tradition of Irving Fisher. New York: J. Wiley.

Nerlove, D.M. Grether \& Carvalho, J.L. 1979. Analysis of Economic Time Series: a Synthesis. New York: Academic Press.

Osborn, D. 1991. "The implications of periodically varying coefficients for seasonal time-series processes." Journal of Econometrics 48: 373-84.

Pierce, D.A. 1978. "Seasonal adjustment when both deterministic and stochastic seasonality are present." In Zellner, A. ed., Seasonal Analysis of Economic Time Series. Proceedings of the Conference on Seasonal Analysis of Economic Time Series 1976, US Department of Commerce, Bureau of Census..

1980. "Data tevisions with moving average seasonal adjustment procedures." Journal of Econometrics 14:95-114.

Pierce, D. A. \& McKenzie 1987. "On concurrent seasonal adjustment." Journal of the American Statistical Association 82:720- 
32.

Plosser, C.I. 1978. "A time series analysis of seasonality in econometric models." In Zellner, A., ed., Seasonal Analysis of Economic Time Series. Proceedings of the Conference on Seasonal Analysis of Economic Time Series 1976, US Department of Commerce, Bureau of Census..

1979. "The analysis of seasonal economic models." Journal of Econometrics 10:147-163.

Priestley, M.B. 1981. Spectral Analysis and Time Series. San Francisco: Academic Press.

Rosenblatt, H.M. 1968. "Spectral evaluation of BLS and Census revised seasonal adjustment procedure." Journal of the American Słatistical Association 63.

Shiskin, J. 1969. "Introductory comments." In Information for the User, the X-11 Variant of the Census Method II. Seasonal Adjustment Program, Bureau of the Census, USA..

Shiskin, J. \& H. Eisenpress 1957. "Seasonal adjustments by electronic computer methods." Journal of the American Statistical Association 52:415-449.

Shiskin, J., A .H. Young \& J.C. Musgrave 1967. "The X-11 variant of the census method II seasonal adjustment program." Bureau of Census, Technical paper 15, US Department of Commerce.

Thomas, J. J. \& K. F. Wallis 1971. "Seasonal variation in regression analysis." Journal of the Royal Statistical Society A 134:57-72.

Wallis, K.F. 1974. "Seasonal adjustment and relations variables." Journal of the American Statistical Association 69:18-31.

1978. "Seasonal adjustment and multiple time series analysis." In Zellner, A., ed., In Seasonal Analysis of Economic Time Series. Proceedings of the Conference on Seasonal Analysis of Economic Time Series 1976, US Department of Commerce, Bureau of Census..

1980. "Seasonal adjustment and readjustment of current data: applications of time-varying linear filters." Mimeo, University of Warwick.

1982. "Seasonal adjustment and revision of current data linear filters for the X-11 method." Journal of the Royal Statistical Society 145: 74-85.

1983. "Models for $\mathrm{X}-11$ and $\mathrm{X}-11 /$ forecast procedures 
for preliminary and revised seasonal adjustment." In Zellner, A., ed., Applied Time Series Analysis of Economic Data A.. Proceedings of the Conference on Applied Time Series Analysis of Economic Data 1981, US Department of Commerce, Bureau of Census..

\section{Appendix A}

Examples on the consequences of seasonal adjustment on estimated relationships.

1) Adjustment by the same filter may cause OLS to be inconsistent:

Let us assume that the true relationships:

$$
x_{t}=\rho x_{t-1}+\theta_{t}
$$

and that seasonality has period 4 so that we use the filter $\left(1-L^{4}\right)$ to adjust data. Define $x_{t}^{a}=\left(1-L^{4}\right) x_{t}$ and $\theta_{t}^{a}=\left(1-L^{4}\right) \theta_{t}$. Then, the OLS estimator of $\rho$ in the regression

$$
x_{t}^{a}=\rho x_{t-1}^{a}+\theta_{t}^{a}
$$

is inconsistent because $E\left(x_{t-1}^{a} \theta_{t}^{a}\right)=-\rho^{3} \sigma_{e}^{2}$

2) Adjustment by different filters causes a change in dynamics and parameters:

Let us assume that the true relationship is

$$
y_{t}=\sum_{j=0}^{4} \alpha^{j} x_{t-j}+\theta_{t},
$$

that $x_{t}$ is non-seasonal so that seasonality in $y$ comes through seasonality in the disturbances and that such seasonality is of period 4 . Hence the relationship with adjusted data is

$$
\begin{aligned}
y_{t}^{a} & =\left(1-L^{4}\right) \sum_{j=0}^{4} \alpha^{j} x_{t-j}+\theta_{t}^{a} \\
& =\sum_{j=0}^{3} \alpha^{j} a_{t-j}+\left(\alpha^{4}-1\right) x_{t-4}-\sum_{j=1}^{4} \alpha^{j} x_{t-j-4} .
\end{aligned}
$$


Thus, the coefficient of $x_{t-4}$ has changed and further lags on the explanatory variables have been added.

3) When the seasonal component is unrelated to the dependent vari. able, OLS is inconsistent whether adjusted or unadjusted data is used.

Assume

$$
x_{t}=x_{t}^{n}+x_{t}^{s},
$$

where $x_{t}^{n}$ and $x_{t}^{s}$ are the non-seasonal and seasonal components of $x_{t}$. In addition, assume that the true relationship is:

$$
y_{t}=\alpha x_{t}^{n}+\theta_{t}
$$

with $E\left(x_{j}^{n} \theta_{j}\right)=E\left(x_{j}^{s} \theta_{j}\right)=E\left(x_{j}^{n} x_{j}^{s}\right)=0 \forall j, j$. Hence, the true relatinship can be written as

$$
y_{t}=\alpha x_{t}+u_{t}
$$

where $u_{t}=\theta_{t}-\alpha x_{t}^{s}$, yielding the following results:

a) Running the OLS regression on unadjusted data entails OLS inconsistent because, in general,

$$
E\left(x_{t} u_{t}\right)=-\alpha E\left[\left(x_{t}^{s}\right)^{2}\right] \neq 0 .
$$

b) Running the OLS regression with adjusted $x_{t}$ implies that $E\left(x_{t}^{s} \nu_{t}\right) \neq 0$, where $\nu_{t}$ are the disturbances in that regression. Hence, OLS of $\alpha$ is inconsistent. 